\section{Lesiones osteolíticas como forma de presentación del linfoma no Hodgkin}

\section{Sr. Director:}

La causa más frecuente de lesiones óseas tumorales son las neoplasias de próstata, mama, pulmón, tiroides y riñón, además de los tumores óseos primitivos y el mieloma múltiple. En los síndromes linfoproliferativos son poco frecuentes la afectación ósea y la hipercalcemia, excepto en adultos con leucemia/linfoma de células T. Se observan cuando la enfermedad progresa en alrededor del 5 al $15 \%$ de los linfomas $(1,2)$.

Presentamos el caso de un varón de 67 años con antecedentes de hipertensión arterial, extirpación de lesión fibroblástica cicatricial en la escápula izquierda y herniorrafía crural izquierda. Consulta por un cuadro de 2 meses de evolución de dolor óseo en hombros, columna lumbar y cadera izquierda, que le interfiere con el sueño y no se alivia con el reposo. En el último mes se acompaña de aumento de partes blandas en cadera izquierda, incremento del dolor, a pesar de realizar tratamiento con AINES orales, y sudoración profusa. En la exploración física sólo destaca un aumento de partes blandas en la cadera izquierda y dos adenopatías inguinales móviles, no dolorosas, y de consistencia aumentada.

En las exploraciones complementarias se objetiva: anemia microcítica (Hb:10.4 mg/dl, VCM: $71.9 \mathrm{fl}$ ) y VSG de $54 \mathrm{~mm}$ a la primera hora; lesiones líticas en el arco anterior de la $10^{\mathrm{a}}$ costilla en la radiografía de tórax y en el borde externo del ala ilíaca izquierda, con masa de partes blandas asociada, en la radiografía abdominal. El TAC torácico y abdominopélvico mostraron hepatoesplenomegalia homogénea, extensa afectación ganglionar, lesión lítica costal derecha, fragmentación de la cortical y línea de fractura en la espina ilíaca anterosuperior izquierda, con masa de partes blandas asociada que infiltra los músculos ilíaco, glúteo menor y mediano.

La biopsia ganglionar demostró proliferación de células linfoides positivas para LCA y CD 20, diagnóstico de linfoma B difuso de células grandes, y la biopsia de médula ósea de infiltración por linfoma. La LDH fue de 551 U/L (N:140-310) y la $\beta 2$-microglobulina $3,17(\mathrm{~N}: 0,30-2,10)$.
En los linfomas cuando la enfermedad progresa se observan lesiones líticas en alrededor del 5 al $15 \%$ de los casos $(1,2)$. El LNH primario de hueso representa menos del $2 \%$ de todos los linfomas en adultos y la mayoría son linfomas B difusos de células grandes $(3,4)$. La forma de presentación más frecuente son las lesiones líticas de huesos largos, que asocian una masa de partes blandas en la mitad de los casos, y dolor óseo que no alivia con el reposo. Las fracturas patológicas afectan con mayor frecuencia a los huesos que soportan el peso $(2,5,6)$.

Mientras el diagnóstico de linfoma primario de hueso no se establezca en función de características inmunohistoquímicas, citogenéticas o moleculares, la diferenciación entre el linfoma primario de hueso con extensión ganglionar y el linfoma ganglionar con afectación ósea se realiza de forma arbitraria. Los pocos estudios inmunohistoquímicos disponibles sólo demuestran la presencia, en el linfoma primario de hueso, de células B con un predominio de cadenas pesadas de $\operatorname{IgG}(7)$.

\section{R. López Rodríguez, U. Anido Hernández, J. Campos Fran- co, E. González Babarro, M. R. Alende Sixto, A. González Quintela}

Unidad Médica de Alta Precoz. Complejo Hospitalario Universitario de Santiago de Compostela. Santiago de Compostela. A Coruña

1. Seymour JF, Gagel RF. Calcitriol: the major humoral mediator of hypercalcemia in Hodgkin's disease and non-Hodgkin's lymphomas. Blood 1993; 82: 1383-94.

2. Roux S, Mariette X. Hematological malignancies and the bone (myeloma excluded). Joint Bone Spine 2000; 67: 264-71.

3. Dubey P, Ha CS, Besa PC, et al. Localized primary malignant lymphoma of bone. Int J Radiat Oncol Biol Phys 1997; 37: 1087-93.

4. Gianelli U, Patriarca C, Moro A, et al. Lymphomas of the bone: a pathological and clinical study of 54 cases. Int J Surg Pathol 2002; 10:257-66.

5. Mulligan ME, McRae GA, Murphey MD. Imaging features of primary lymphoma of bone. AJR 1999; 173: 1691-7.

6. Stokes SH, Walz BJ. Pathologic fracture after radiation therapy for primary non-Hodgkin's malignant lymphoma of bone. Int J Radiat Oncol Biol Phys 1983; 9: 1153-9.

7. Pettit CK, Zukerberg LR, Gray MH, et al. Primary lymphoma of bone: a B-cell neoplasm with high frequency of multilobated cells. Am J Surg Pathol 1990; 14: 329-34. 